\title{
Gold Technology in Ancient Egypt
}

\author{
MASTERY OF METAL WORKING METHODS
}

\section{T. G. H. James}

The British Museum, London

The peculiar qualities of gold that have made it so valuable a material in industry and art were appreciated by the ancient Egyptians from the earliest historical times. In tombs of the First Dynasty, which may be dated to at least 3000 B.C., objects, or parts of objects, have been found, either made wholly of gold or embellished in part with gold. Already at this early period gold wire of a kind was used, and beaten gold was employed to sheath small objects and, as foil, to cover the tops of small vessels. The mastery of techniques indicated by the scanty remains found in the much plundered tombs of this and later periods reveals the extent to which Egyptians understood the possible uses of gold. This mastery received its greatest demonstration for modern observers, however, in the tomb equipment found in the burial of King Tutankhamun who died in about 1352 B.C.

Gold dominates the impression created by the objects from this tomb, but the actual quantity of gold used is undoubtedly far less than the impression suggests. Some of the objects are made of solid gold, such as the innermost coffin which weighs about 110 kilograms, but the majority of 'golden' objects are gilded only, either with gold foil or with gold leaf. Nevertheless, the contents of the tomb provide a wonderful field for the study of gold technology in the ancient world - a field which so far has not been properly exploited. Not only is the quantity of material large and varied, but it belongs to a period when gold was particularly employed by the Egyptians, when one foreign ruler, writing to the King of Egypt, declared his belief that gold was as common as dust in Egypt.

Most of the gold used in Egypt in antiquity was obtained from the mountainous region which lay between the Nile and the Red Sea. The area exploited by the Egyptians stretched for about five hundred miles from approximately the latitude of the modern town of Quft southwards, deep into what is now the Northern Sudan. Metal from the northern, central and southern parts of this area was called 'Gold of Coptos', 'Gold of Wawat', and 'Gold of Kush'. Ancient inscriptions record the annual production of these districts in a few instances, and it would seem that the mines of the Wawat region were by far the most profitable. But not sufficient details have survived to allow any satisfactory record of production to be compiled.

Gold was retrieved both from alluvial deposits and from quartz rock. Modern surveys in the Eastern Desert of Egypt and the Northern Sudan have discovered considerable traces of ancient exploitation of alluvial sands and gravels, and it is probable that in

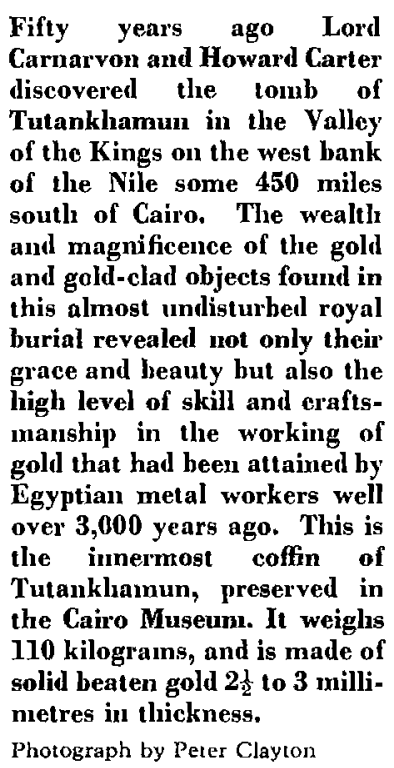

Fifty years ago Lord discovered the tomb of Tutankhamun in the Valley of the Kings on the west bank the Nile some 450 miles soutli of Cairo, The wealtir and gold clad objects found in this almost undisturbel royal burial revealed not only their grace and beauty but also the high level of skill and craftsthe working of gold that had heen attained by over 3,000 years ago. This is the innermost coffin of Tutankluanun, preserved in the Cairo Museum. It weighs 110 kilograms, and is made of netres in thickness.

Photograph by Peter Clayton

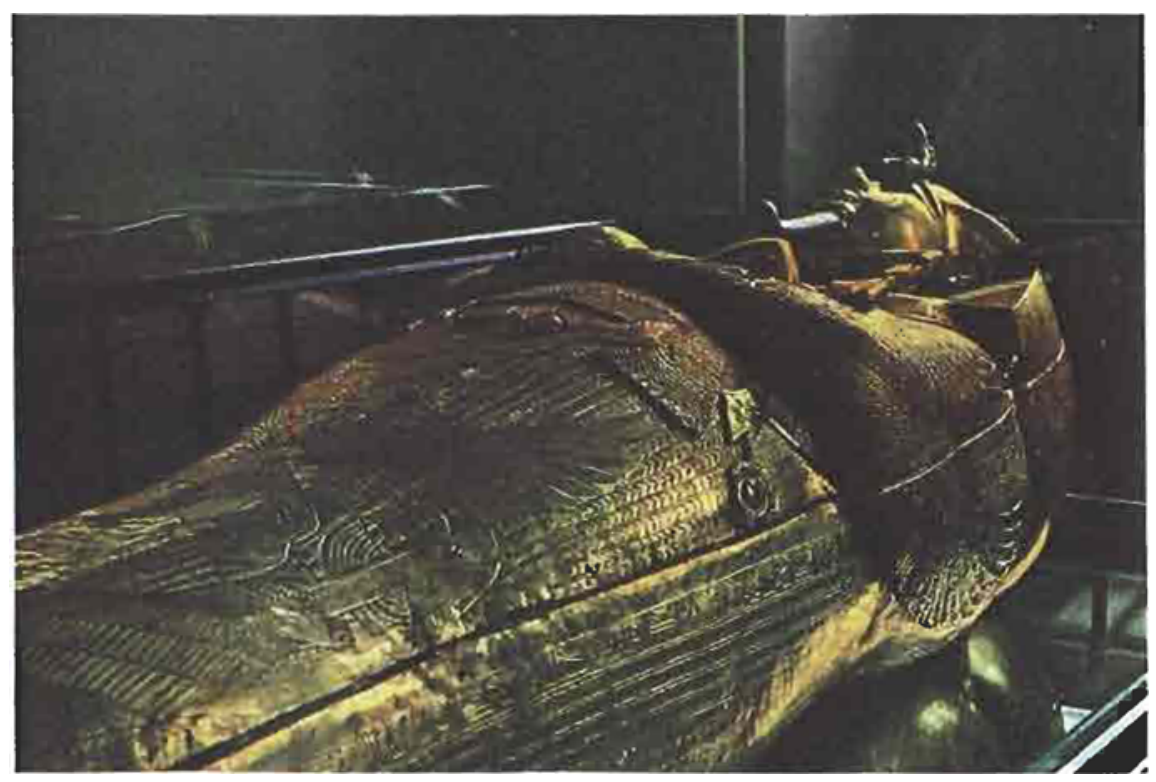


The exhibition of the treasures from the tomb of Tutankhamun which opened at the British Museum at the end of last month clearly demonstrates the extent to which the Egyptians understood the possible uses of gold. The funerary mask of Tutankhamun, who died in about 1352 B.C., forms the focal point of the exhibition. It is made of beaten and burnished gold inlaid with semi-precious stones and coloured glass pastes. On the forehead, cast by the lost wax process, are the solid gold insignia of the vulture goddess Nekhbet and the uraeus or cobra Buto.

Photograph by Peter Clayton

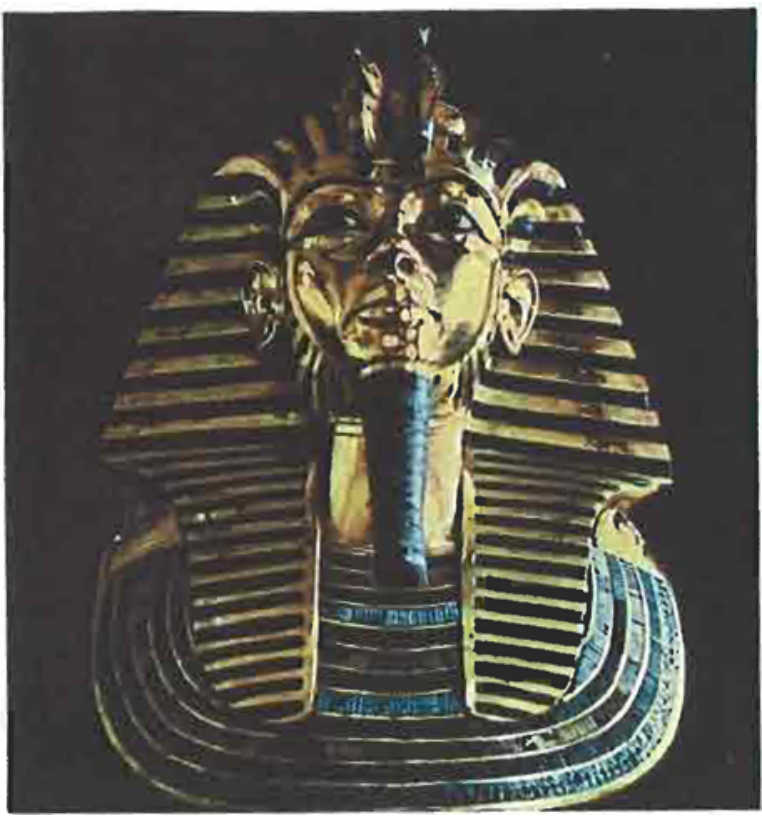

method of transport was by donkey. It is, however, wholly consistent with the Egyptian attitude towards technical activities that such laborious journeys would have been accepted readily as a necessary part of the overall process of obtaining the precious metal.

A large number of ancient workings in gold-bearing quartz veins have been identified in the Eastern Desert, and some mines reach a depth of three hundred feet or more. No ancient Egyptian records describe the way in which gold was extracted but an account written by Agatharchides, a Greek writer who lived in the second century B.C., preserved at second-

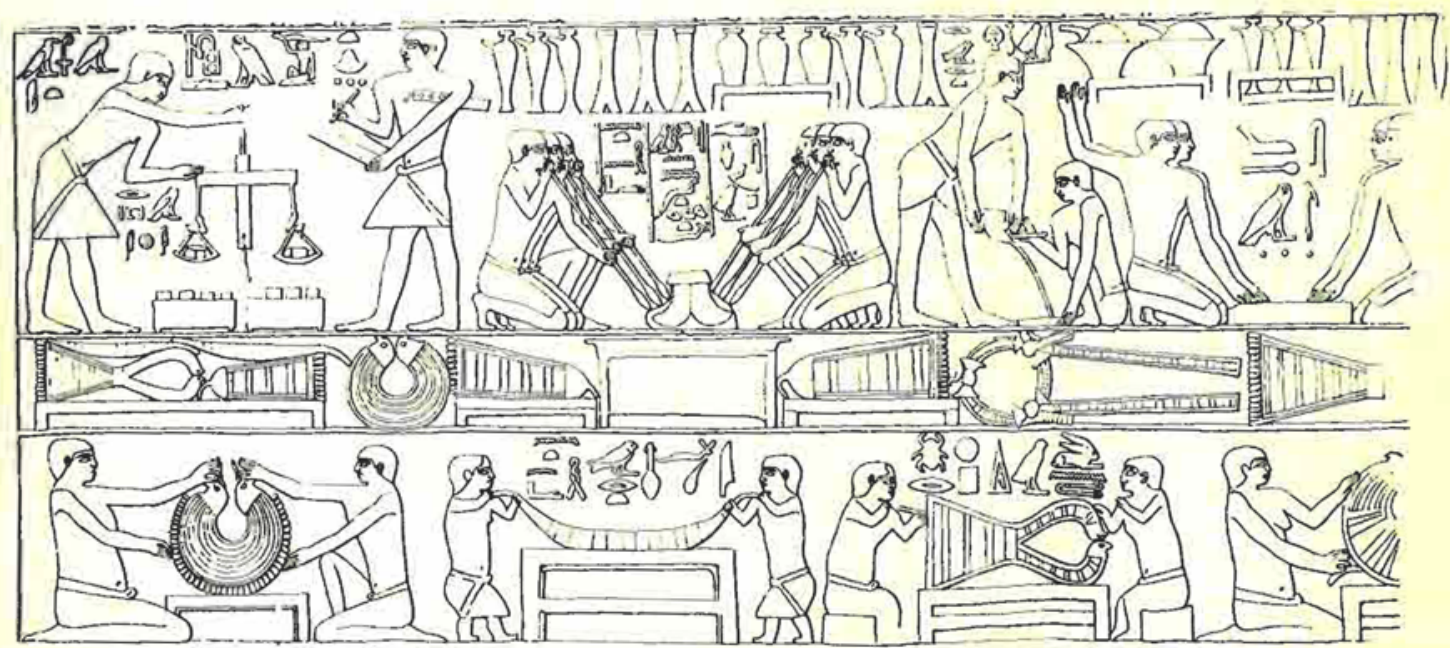

The melting, casting, and working of gold are well illustrated in a relief from the tomb of Mereruka dating from about 2300 B.C., at Saqqara. The upper register shows first the metal being weighed out and checked by a scribe, six men using blowpipes on a charcoal-fired melting furnace, the pouring of the molten metal into a flat mould and then the beating of the ingot into sheet, using stones held in the hand. The centre band shows some of the types of ornaments made, while the lower part of the rehief shows two men finishing a collar and then dwarfs working on elaborate pieces of jewellery. 


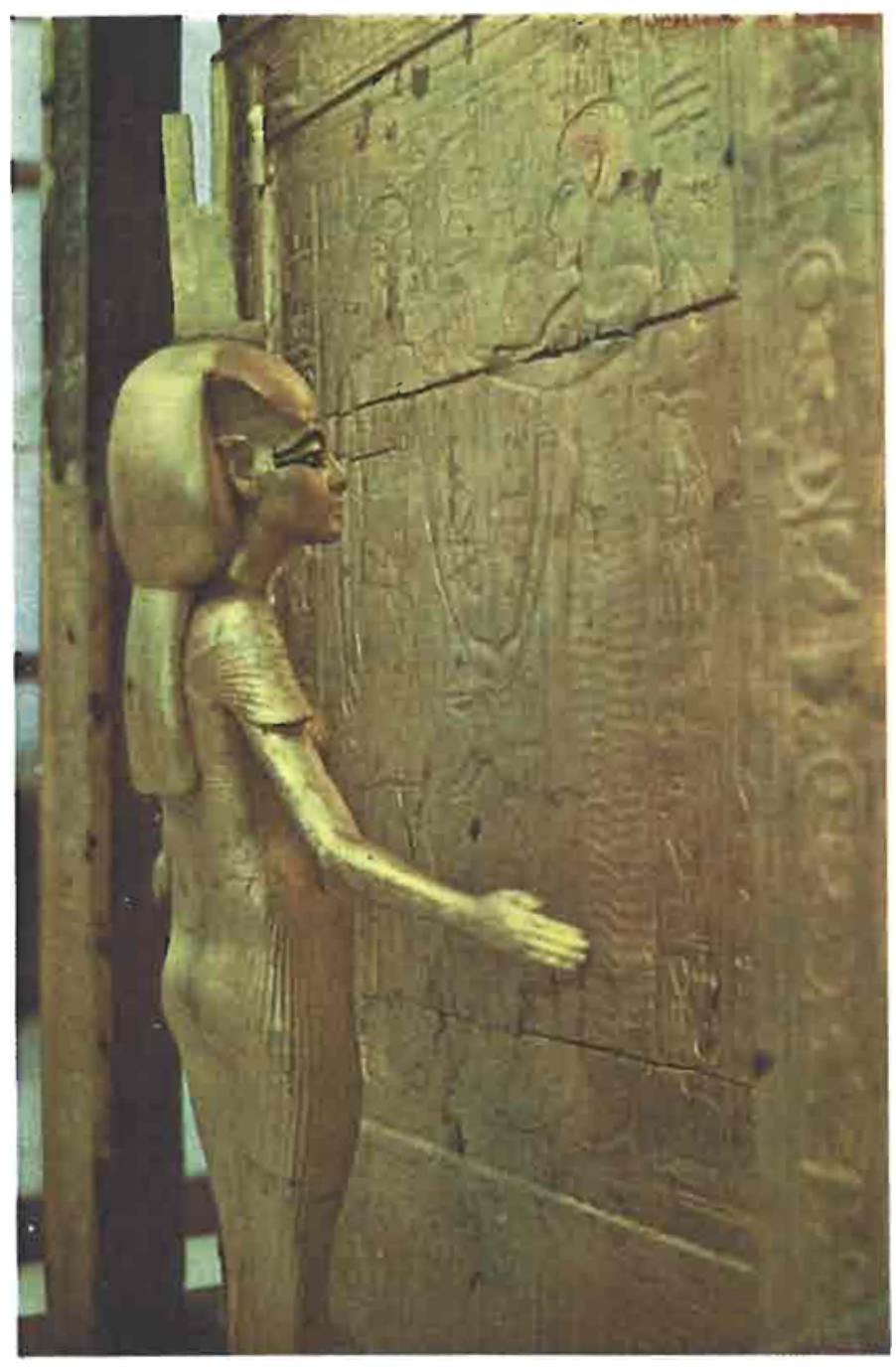

At a very early period Egyptian gold workers discovered that gold could be hammered into thin sheets and that by this means they could use it not only more economically but also with greater effect. Frequently the wooden structures on which gold sheets were to be fastened were first carved with texts and designs. The gold sheets were then beaten in position, so receiving raised impressions of the texts and decorations. When gold leaf was used, it was applied to the decorated wooden surface over a layer of fine plaster. This example of gilded wood is a shrine from the Tutankhamun tounb, guarded on eacli of its four sides by a goddess, in this illustration the goddess Isis.

Photograph by Peter Clayton

factured, although no wholly satisfactory explanation has yet been proposed for the technique used to produce it. Gold objects with this rose-pink colour are almost all of royal ownership. For most purposes gold was used as it came, its colour would vary from batch to batch, and only a little trouble was taken to match colour over a large piece of work. Scenes of gold delivery from Kush show that it was made into hollow rings for transport. In this form it was handed over to the gold workers in royal and temple workshops to be used for the many purposes for which it was required.

It has been stated that Egyptian gold workers developed most of the techniques employed by modern craftsmen, and indeed surviving artefacts tend to confirm this claim. At a very early period craftsmen dis-

hand, gives a description of the methods used in Egyptian mines in later times. The rock was first broken up by the use of fire and hammers; it was then crushed in mortars into small pieces, and finally ground to powder. This powder was washed on a sloping surface, and the gold dust thus recovered was fused in crucibles into small nuggets. Archaeological evidence suggests that only some of these processes were carried out at the mining site. Possibly the rock was reduced to the powder state there, while the washing and fusing took place at special stations on the banks of the Nile.

There is no evidence that the Egyptians used any technique for refining the gold they acquired from their mines and alluvial deposits. In consequence, analyses of gold used in Egypt in antiquity reveal a wide range of impurities, and inevitably the colour of ancient gold varies considerably. Most of these colour variations are fortuitous, due to the presence of other metals, for example, silver or copper; but one attractive variant, gold with a rose-pink surface film, seems possibly to have been deliberately manucovered that gold could be hammered and that by so doing they could use it not only more economically, but also with greater aesthetic effect. The gilded equipment found in the tomb of Queen Hetepheres, the mother of Cheops, the builder of the Great Pyramid, demonstrates strikingly how successfully goldsmiths had mastered the technique of sheathing with gold as early as 2600 B.C. Among the tomb furniture was a bed canopy, the framework of which consisted of four corner-posts of rectangular section, ten side poles of circular section, five roofing poles of circular section, three base boards of rectangular section, and four frame boards of rectangular section joining the corner posts at the top. All these members were between 2.20 metres and 3.20 metres in length, and consisted of wooden cores covered with fairly heavy gold sheeting. In most cases single sheets of gold were used to cover each member, small gold tacks being employed to fasten the gold in position. In the cases of the corner-posts the gold displayed inscriptions and decorations which were obtained by beating the sheeting on to the wooden 
cores which had first been carved with the desired texts and patterns.

The use of heavy gold sheeting remained a favourite method of gilding throughout Egyptian history, and it must be suspected that the extravagance of the method was partly responsible for its continued employment. Conspicuous display was a characteristic of Egyptian royal behaviour. The Egyptian craftsmen, however, had early on discovered that equally satisfactory results could be obtained by using much thinner foil and even gold leaf. The foil or leaf was rarely applied directly to the object to be gilded. First of all the object was covered with a thin layer of specially fine plaster, and the gold then placed in position with the help of some kind of adhesive, the nature of which has not been established.

Scenes of the beating of gold are to be found in several Egyptian tombs, and modern gold-beaters have declared that the attitudes adopted by the beaters and the nature of the anvil and hammer used suggest that the ancient beating technique was very similar to that used in Europe since at least mediaeval times. Furthermore, the examination of examples of gilding with leaf have shown that the size of the leaves used was virtually the same as that employed today, and that the thickness of the finest ancient leaf is scarcely greater than standard leaf thicknesses obtained by modern beaters. There is no evidence to suggest that the Egyptians made a terminological distinction between gold leaf and gold foil, but it is probable that specially skilled beaters were used to produce the former.

Gilding by leaf was used not only for wooden objects, but also for metal objects and even for the illumination of painted scenes on papyrus. Not a great many examples of this last use have survived, but a particularly happy one can be found on a funerary payprus in the British Museum, prepared for a certain Neferronpet, who lived about 1300 B.C. His title is given as 'chief of the makers of thin gold', and it may be surmised that he was able to make use of his special position to have gold used in the vignettes of his papyrus. Much of the gold is lost, but a laboratory examination of the surviving fragments has showed that the thickness of the leaf used was about 6 microns or $0.006 \mathrm{~mm}$.

The skill of Egyptian goldsmiths is best revealed in Egyptian jewellery, a field in which technical prodigies were accomplished. Among the most effective techniques practised from about 2000 B.C. (if not earlier) was cloisonné work. Most elaborate designs built up of small pieces of glass, semi-precious stones and faience, fitted into gold cloisons, were carried out with absolute technical confidence. The cloisons were made of small strips of gold sheet fitted to a base-plate either by colloid hard soldering or by soft soldering. In the latter method an alloy of gold of lower melting point was used with a flux which may have been natron, a naturally occurring material consisting chiefly of sodium carbonate and sodium bicarbonate.

Open furnaces fired with charcoal and intensified by foot-operated bellows or by blow-pipe, were commonly employed in working gold; many tomb scenes depict craftsmen engaged in the processes of jewellery making. The inlays in cloisonné jewellery were fastened in place by a cement-like paste. So far it has not been convincingly established that true enamel was produced in Egyptian cloisonné work.

Small elements in jewellery were made either by casting or by the use of moulds. Casting was effected in the case of small modelled objects by the lost-wax process, although the somewhat fussy technique was not used for most simple objects. Many gold beads and decorative elements in elaborate jewellery were made from gold foil. For these open stone moulds
A pair of bracelets belonging to Rameses II, who beeame king about fifty years after the death of Tutankhamun. The decoration of the bracelets is most skilfully achieved, with gramules and plain, beaded, and twisted wires soldered into position, most probably by the colloidal process. This technique involved coating the parts with ground copper carbonate mixed with glue. On heating on a charcoal furnace with a blowpipe the copper carbonate was reduced to metal and a thin layer of copper-gold alloy was formed, giving a bonded joint.

Photograph by courtesy of Thames \& Hudson Ltd

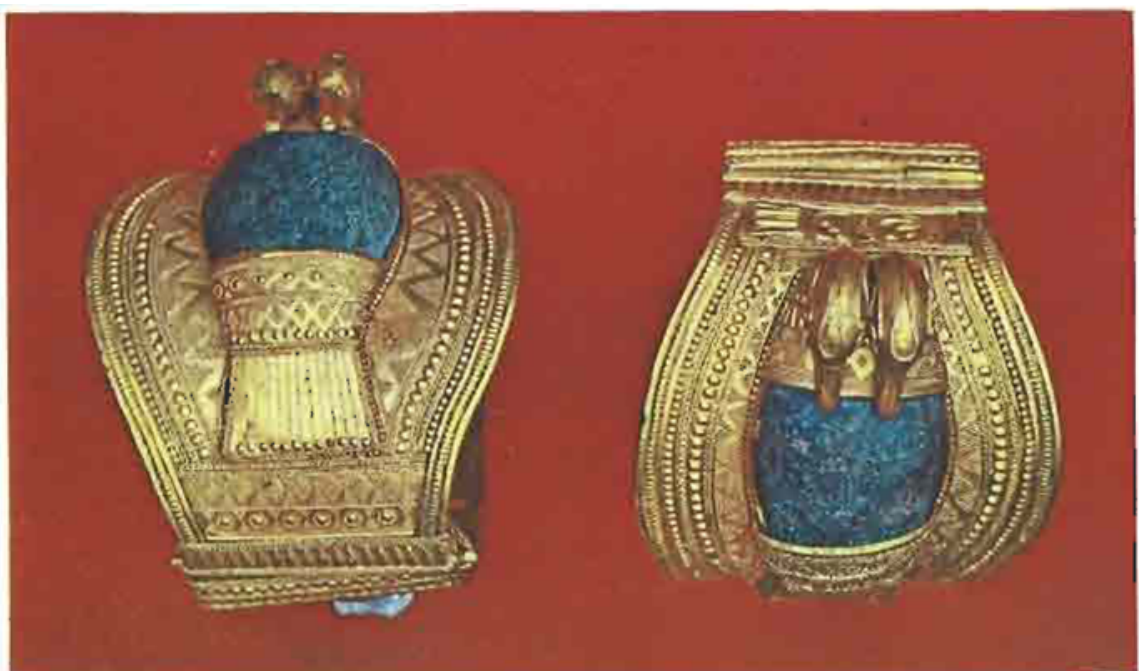




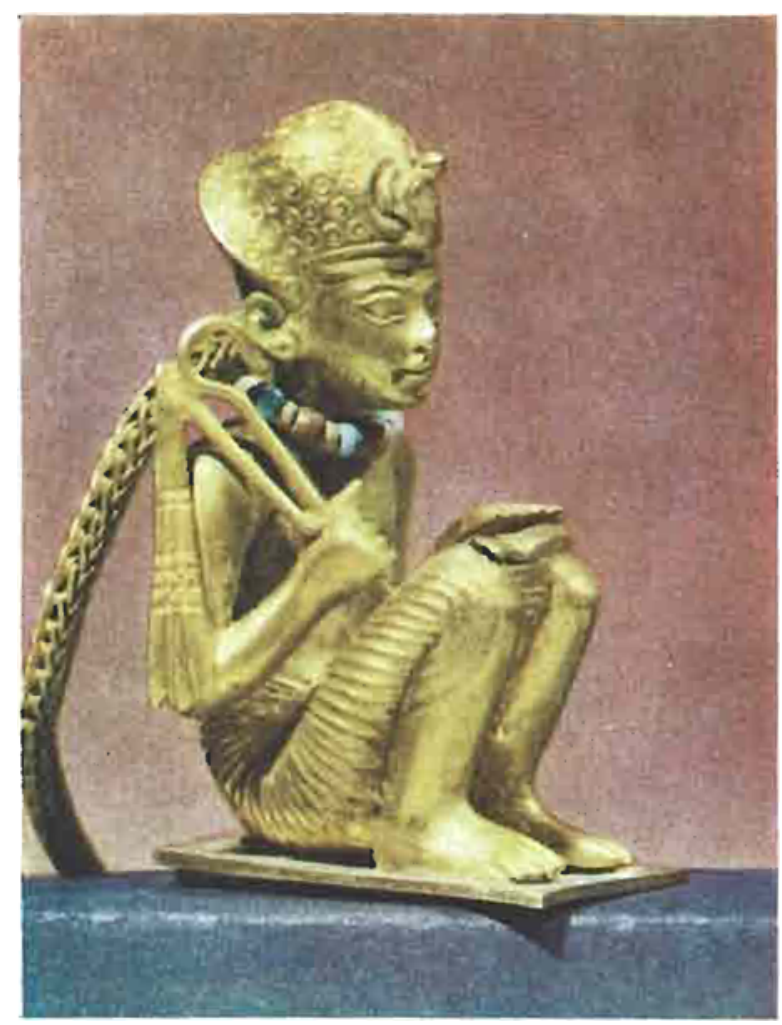

Small objects were produced by the well-known lost wax process of casting. This tily statuette of Tutankhamun, only two inehes in height, is cast in solid gold. It was found in a nest of sinall coffins in the tomb.

Photograph by F. L. Kenett, (c) George Rainbird Ltd

were employed, the gold foil being beaten into the designs cut in the moulds to obtain the necessary shape, and then fitted with a flat back-plate which was soldered into position. Gold wire, which was also commonly used, may have been manufactured by the drawn process, although this has not been estab- lished for most periods of Egyptian antiquity. In general, wire was probably mostly made from rolling thin strips of gold sheet.

At the height of Egyptian craftsmanship in the period which includes the reign of Tutankhamun (about 1500 to 1300 B.C.), jewellers embellished their work with gold granulation. The granules were very fine, but not quite as remarkable as those made by Etruscan jewellers at a somewhat later date. The granules were probably made by cutting up gold wire into small pieces which were then heated and rolled between two flat surfaces.

The considerable quantities of gold used by the ancient Egyptians provide the impression that at most periods large supplies were available. It should be remembered, however, that gold was mined as a royal monopoly and only small quantities would have come into the hands of private persons in the normal way. Most gold therefore was concentrated in royal possession and in the treasuries of the temples. It is also probable that much gold was used time and again in antiquity. Kings had no scruple about stripping the work of their predecessors, and much gold was used for architectural decoration. Furthermore, the craft of tomb-robbing was highly developed, and it may be supposed that the gold in most tombs was returned to circulation through unorthodox channels within a relatively short time after burials were made. Even in periods when Egyptian royalty was weak, Egyptian goldsmiths had material to work on, but their greatest achievements were always made when gold was most plentiful. The treasures from the Tomb of Tutankhamun demonstrate this fact overwhelmingly; it is a remarkable piece of good fortune that this tomb was never completely stripped by the ancient tomb robbers.
Among the jewels of the Princess Klnnumet (c. 1875 B.C.) found in her tomb at Dalıslnur were a number of examples of superb craftsmanship. This circlet, preserved in the Cairo Museum, is made of gold wire, to which are soldered dozens of little gold flowers with carnelian centres and turquoise petals, the frail structure being reinforeed at six points by a large cruciform ornament, again in gold inlaid with semi-precious stones. The wire was made by rolling very narrow strips of gold cut from thin sheet.

Photograph by courtesy of Thames \& Hudson Ltd

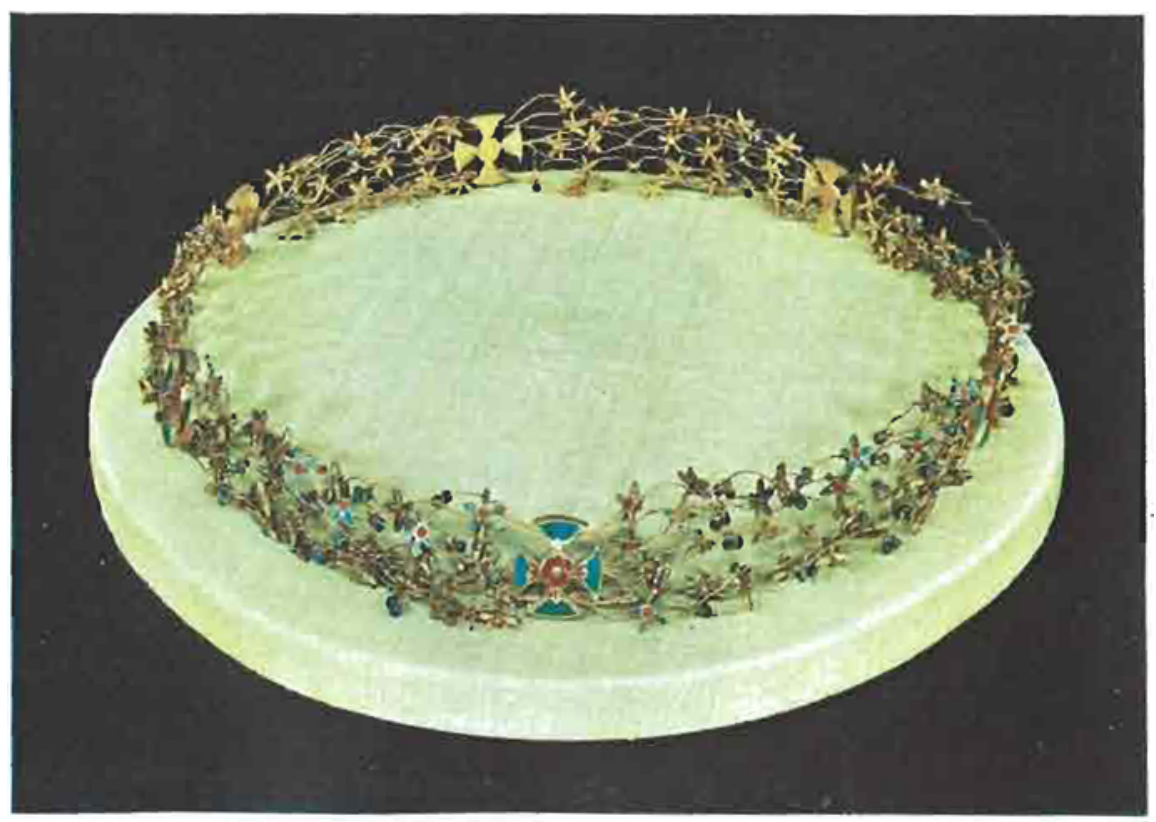

